\title{
Factors Affecting Runoff Retention Performance of Extensive Green Roofs
}

\author{
Yongwei Gong ${ }^{1}$, Dingkun Yin ${ }^{1} \mathbb{C}$, Xing Fang $2,3{ }^{-1}$ and Junqi $\mathrm{Li}^{1,4, *}$ \\ 1 Key Laboratory of Urban Stormwater System and Water Environment, Ministry of Education, \\ Beijing University of Civil Engineering and Architecture, Beijing 100044, China; \\ gongyongwei@163.com (Y.G.); lumoskun@163.com (D.Y.) \\ 2 Department of Civil Engineering, Auburn University, Auburn, AL 36849-5337, USA; xzf0001@auburn.edu \\ 3 Beijing Cooperative Innovation Research Center on Architectural Energy Saving and Emission Reduction, \\ Beijing University of Civil Engineering and Architecture, Beijing 100044, China \\ 4 Beijing Advanced Innovation Center for Future Urban Design, Beijing 100044, China \\ * Correspondence: li6700@163.com; Tel.: +86-10-6832-2094; Fax: +86-10-6120-9291
}

Received: 8 August 2018; Accepted: 4 September 2018; Published: 10 September 2018

check for updates

\begin{abstract}
The runoff retention effectiveness of 10 extensive green roof (EGR) modules (100 mm substrate planted Sedum lineare Thunb.) were analyzed in Beijing for 22 rainfall events (2.4-46.4 mm) from 1 July to 30 September 2017. Differences between minimum inter-event dry periods, module scales, substrate hydraulic conductivity and depths, drainage layer types and rainfall characteristics were examined to study their correlation to the retention performance of EGRs. In general, EGRs with lower substrate hydraulic conductivity, deeper substrate and lower rainfall depth had higher runoff retention performance. By comparsion, no siginificant correlation was found between rainfall duration, prior dry period, average rainfall intensity, drainage layer type and EGR runoff retention rate. Analyses of variance (ANOVA) and Tukey tests supported these results. Low or moderate rainfall $(<15 \mathrm{~mm})$ may or may not have an effect, but heavy rainfall $(>25 \mathrm{~mm})$ definitely affects the EGR retention performance of the next rainfall event.
\end{abstract}

Keywords: extensive green roof (EGR); runoff retention rate (R3); minimum inter-event dry period (MIDP); influencing factors; rainfall characteristics

\section{Introduction}

In the process of rapid urbanization, cities' impervious surface areas have rapidly increased. Urban local flooding caused by rainwater has severely affected the aquatic urban environment. Many cities in China have experienced flood events and suffered heavy property and human life losses [1]. In recent years, 30 cities in China have started pilot construction of 'sponge cities' and many low-impact developments (LID) facilities have been constructed to alleviate urban local flooding problems [2]. The 'green roof' is one of the typical forms of LID systems in sponge cities, regulating both quantity and quality of rainfall runoff [3]. Roof areas, also known as the 'fifth façade' of the building, have always been virgin land in the city yet to be reclaimed, and are often ignored or forgotten. Compared with other LIDs, green roofs not only control rainfall runoff without taking up extra urban land, but also provide good thermal insulation and significant energy-saving abilities $[4,5]$.

Green roofs mainly contain a vegetation layer, a substrate layer and a drainage layer, and are classified as either intensive green roofs or extensive green roofs (EGR) depending on the depth of the substrate layer [6,7]. Many previous studies have shown that one of the most important capabilities of green roofs is to reduce runoff [8-11]. Many factors affect the hydrological performance of green roofs, such as different substrate depth and plant cover [6,12-14]. 
Many studies have also shown that the composition and thickness of the substrate is significantly related to the water retention rate, which improves as the thickness of the substrate layer is increased $[6,15,16]$. Soulis et al. [6] found that when the thickness of the substrate was doubled from $8 \mathrm{~cm}$ to $16 \mathrm{~cm}$, the average retention rate increased from $4.2 \%$ to $17.5 \%$ in the monitoring period, since there were different plant species in the vegetation layer. Van Woert [16] also found that during the monitoring period, the retention rate increased by $0.9 \%$ when the substrate increased from $2.5 \mathrm{~cm}$ to $4 \mathrm{~cm}$, and increased by $2.2 \%$ when the substrate increased from $4 \mathrm{~cm}$ to $6 \mathrm{~cm}$. Stovin et al. [12] demonstrated the effect of different hydraulic conductivities on the retention capacity of the substrate. Their results show that greater hydraulic conductivity reduces retention capacity. In addition to the substrate layer, the abundance of plants in the plant layer may also have some influence on the retention capacity. In Zhang's study [17], it was found that when there is a range of plants in the vegetation layer rather than only one type, runoff retention performance was weakened, but other studies have shown that the abundance of plant types is not related to the retention performance [14].

Many studies have been conducted on the impact of rainfall characteristics on the retention performance of green roofs. Rainfall depth seems to be the most significant factor that affects runoff retention rather than rainfall duration, intensity, or the antecedent dry period $[3,8,12,18]$. Hakimdavar et al. [18] believed that the runoff retention rate gradually decreased with longer periods of rainfall, but the effect of antecedent dry period and rainfall intensity was less. However, Alfredo et al. [19] showed that increased rainfall intensity results in a downward trend in green roof retention rates.

Thus, it is seen that the runoff retention performance of the green roof depends on many factors, and its contribution to the retention of stormwater runoff cannot be underestimated. However, some studies have shown that, in areas of heavy rainfall, green roofs have poor ability to reduce rainfall runoff; both peak time delays and peak flow reductions are not as effective as for small rainfall events. Therefore, it is necessary to consider whether or not green roof technology is useful in the management of stormwater runoff under particular local conditions, and cannot be generalized [20].

The purpose of the study is to comprehensively investigate the effects of multiple factors on the runoff retention of green roofs. The influencing factors investigated in this study include the scale of the EGR modules, the substrate's hydraulic conductivity, substrate depth, drainage layer, and rainfall characteristics. There are no similar studies that have been conducted before. The runoffs of a series of EGR modules were monitored for natural rainfall events and corresponding runoff retention rates were determined and analyzed. The results provided information on the extent to which these factors are related to the runoff retention performance of green roofs, as a guide to the construction of the green roof in practical projects.

\section{Materials and Methods}

\subsection{Site Description and Experimental Setup}

Ten square EGR modules and a normal roof module were monitored (Figure 1, internal length of 50-150 cm $\times 24-34 \mathrm{~cm}$ deep) placed on the roof of the stormwater laboratory in the Beijing University of Civil Engineering and Architecture (BUCEA) $\left(39^{\circ} 44^{\prime} 58^{\prime \prime} \mathrm{N}, 116^{\circ} 16^{\prime} 57^{\prime \prime} \mathrm{E}\right)$, Beijing, China. The annual average air temperature of the study area was approximately $12^{\circ} \mathrm{C}$ and average annual rainfall was $626 \mathrm{~mm}$, most of which falls from July to September, and was typical of a continental monsoon climate.

The EGR modules were made of polyvinyl chloride; two $2.0 \mathrm{~cm}$-diameter drainage pipes were installed in the base of each module and a $2.5 \mathrm{~cm}$ overflow pipe was set $4.5 \mathrm{~cm}$ above the soil (substrate) surface of the vegetation layer (Figure 1). The EGR modules had a 1\% slope toward the drainage pipes within each module to ensure unobstructed drainage. A complete EGR system was placed inside each module, comprising a $2.0 \mathrm{~cm}$ thick ceramsite or 'bump' plastic drainage board and geotextile filter layer (design density $250 \mathrm{~g} / \mathrm{m}^{3}$ ). Figure 1 is a schematic cross-section and side view of a green roof module. 


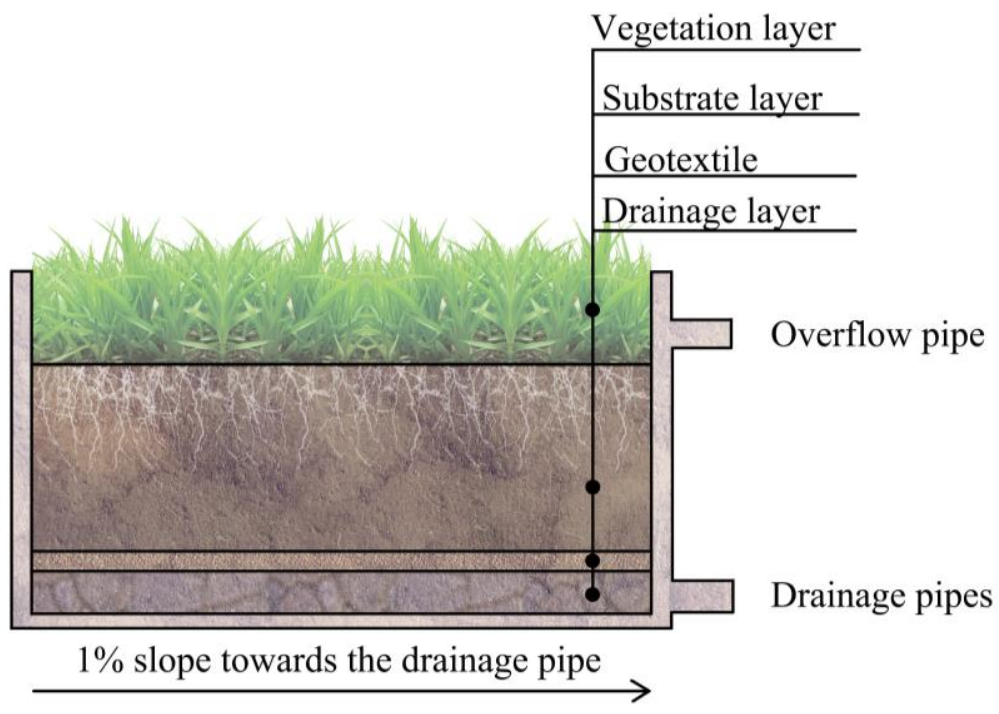

Figure 1. Schematic diagram of the extensive green roof module used this study.

\subsection{Extensive Green Roof (EGR) Plants and Substrates}

The detailed information of 10 EGR modules monitored in this study are listed in Table 1. These 10 EGRs were designed to allow us to study the impact of multiple factors on the runoff retention rate; therefore, the EGRs varied the size, substrate soil and depth, and drainage layer; which will be further explained in Section 3 (results and discussion). Two kinds of substrate were used: an ultra-low-weight substrate, and improved soil substrate. The ultra-low weight substrate is a commercially available inorganic implant substrate for roof greening. It is a kind of "artificial substrate" which is made of non-metallic minerals according to the physical and chemical properties of the soil and the physiological characteristics of the plant. It has low density, drains well, and easy to handle during construction. The improved soil is a mixture of pastoral soil, turf soil, and pine needles (3:4:3 weight ratio), which complied with the recommended technical specifications for planted roof substrates. The pastoral soil was used as substrate in our previous study [21] and was not used here since pastoral soil became easily compacted.

Table 1. Detailed information of the 10 extensive green roof (EGR) modules monitored and analyzed in the study.

\begin{tabular}{|c|c|c|c|c|}
\hline Modules $^{1}$ & Quantities & Substrate Type & $\begin{array}{l}\text { Substrate } \\
\text { Thickness }\end{array}$ & Drainage Layer \\
\hline TID100-0.5 & 4 & Improved soil & $100 \mathrm{~mm}$ & Bump plastic drainage board \\
\hline TID150-0.5 & 1 & Improved soil & $150 \mathrm{~mm}$ & Bump plastic drainage board \\
\hline TID200-0.5 & 1 & Improved soil & $200 \mathrm{~mm}$ & Bump plastic drainage board \\
\hline TUD100-1.5 & 1 & Ultra-low weight substrate & $100 \mathrm{~mm}$ & Bump plastic drainage board \\
\hline TIC100-0.5 & 1 & Improved soil & $100 \mathrm{~mm}$ & Ceramsite \\
\hline TID100-1.0 & 1 & Improved soil & $100 \mathrm{~mm}$ & Bump plastic drainage board \\
\hline TID100-1.5 & 1 & Improved soil & $100 \mathrm{~mm}$ & Bump plastic drainage board \\
\hline
\end{tabular}

Sedum lineare Thunb. was planted in the vegetation layer for all 10 EGRs since it is widely used, tolerates cold and drought well, and does not require excessive maintenance. Another two plants (Angiospermae and Sedum aizoon L.) were also used before [21] but the previous study shows the vegetation layer had little effect on the runoff retention of EGRs. In this study, we also had EGRs 
where Kalimeris and Angiospermae were planted; under cold weather conditions in Beijing, they either did not survive or grew poorly so that these EGRs were not monitored and no results about them are presented hereafter.

\subsection{Data Collection and Analysis}

Digital RG3-M, HOBO rain gauges (Onset, Bourne, MA, USA) were used to monitor the runoff from the EGR modules; the two drainage pipes in each module were connected to one rain gauge by two plastic tubes, as in our previous study [21]. The instrument recorded outflow per minute from the module during rainfall to an accuracy of $0.2 \mathrm{~mm}$. All the hydrological measurements were taken from individual modules. Precipitation data was collected using a HOBO U30 data logger (Onset, Bourne, MA, USA) installed on the roof of the stormwater laboratory. The rainfall events were grouped or separated by three minimum inter-event dry periods (MIDP) to assess the effect of the rainfall-event separation methods on the runoff retention of EGRs [22]. Any rainfall that exceeded $0.2 \mathrm{~mm}$, and had an inter-event period or antecedent dry period equal to or greater than an MIDP (6 or 12 or $24 \mathrm{~h}$ ), was taken to be an independent rainfall event. The runoff retention rate (RRR or R3, \%) for each rainfall event and EGR was defined as:

$$
\mathrm{R} 3=\frac{(\text { volume of runoff from normal roof module })-(\text { volume of runoff from EGR module })}{(\text { volume of runoff from normal roof module })}
$$

where R3 is the proportion of runoff volume captured (not discharged) by the green roof module (\%). The 'normal roof module' was a concrete roof module; and basically $100 \%$ of the rain falling on it was converted into runoff so that the runoff volume was equal to the rainfall depth times the module area.

The hydraulic conductivity, or saturated infiltration coefficient, $\mathrm{K}$, were measured by ring shear testing. For the improved soil, average $\mathrm{K}=9.53 \times 10^{-5} \mathrm{~m} / \mathrm{s}$ from repeated measurements; and for the ultra-low weight substrate, average $\mathrm{K}=3.94 \times 10^{-4} \mathrm{~m} / \mathrm{s}$. These values meet the requirements of technical specifications for green roofs.

The effect of various influencing factors on runoff retention rate R3 for EGRs was analyzed using one-way analysis of variance (ANOVA). Tukey's test ( $\alpha=0.05$ significance level) was used to identify the significance of differences between the means of two or more data groups. When variance analysis gives $p \leq 0.05$, the influencing factor has a strong or significant impact on the mean R3 for the particular type of green roof; $p>0.05$ indicates that the factor is not significant (95\% confidence level).

\section{Results and Discussion}

\subsection{Runoff Retention of EGRs under Different Minimum Inter-Event Dry Periods (MIDPs) and Rainfall Depths}

Rainfall had a strong seasonal variation during the monitoring period in 2017: $88.2 \mathrm{~mm}$ in July, $195.8 \mathrm{~mm}$ in August and $13.8 \mathrm{~mm}$ rainfall in September, totaling $297.8 \mathrm{~mm}$. In the study period 1 July-30 September 2017, 11 rainfall events (Table 2) were unaffected by three MIDPs, since their antecedent dry periods already exceeded $24 \mathrm{~h}$. There were 15 rainfall events (Table 2) with rainfall depths ranging from 3.2 to $46.4 \mathrm{~mm}$ (Figure 2a) when the 24-h MIDP was used to divide the rainfall events, as well as 18 rainfall events using 12-h MIDP and 22 events with rainfall depths ranging from $2.4 \mathrm{~mm}$ to $46.4 \mathrm{~mm}$ using 6-h MIDP (11 of these events are listed in Table 2, and 11 in Table 3). The duration of the monitored rainfall events ranged between $10 \mathrm{~min}$ to $3793 \mathrm{~min}$ when using the 24-h MIDP, and $10 \mathrm{~min}$ to $2446 \mathrm{~min}$ using the 12-h or 6-h MIDPs.

The R3 (\%) of EGRs were affected by various factors: plant types, substrate thickness, rainfall characteristics, etc. The observed R3 of four TID100-0.5 EGRs ranged from $12.1 \%$ to $100 \%$ in this study. It should be noted that no discharge or R3 data was available for one of the TID100-0.5 modules on 4 July and 26 July 2017, due to equipment failure. 
Table 2. Details of 15 rainfall events using $24 \mathrm{~h}$ minimum inter-event dry period (MIDP).

\begin{tabular}{|c|c|c|c|}
\hline Date & $\begin{array}{l}\text { Rainfall Depth } \\
(\mathrm{mm})\end{array}$ & $\begin{array}{l}\text { Duration } \\
\text { (min) }\end{array}$ & $\begin{array}{l}\text { Inter-Event/Antecedent Dry Period } \\
\text { (d) }\end{array}$ \\
\hline 4 July $2017^{1}$ & 24.4 & 498 & 8.4 \\
\hline 6 July $2017^{1}$ & 18.8 & 434 & 2.2 \\
\hline 7 July $2017^{1}$ & 4.4 & 10 & 1.2 \\
\hline 14 July $2017^{1}$ & 8.4 & 625 & 6.9 \\
\hline 18 July $2017^{2}$ & 8.6 & 799 & 2.9 \\
\hline 20 July $2017^{2}$ & 19.2 & 841 & 2.1 \\
\hline 26 July $2017^{1}$ & 4.4 & 197 & 4.8 \\
\hline 2 August $2017^{1}$ & 41.8 & 2446 & 6.4 \\
\hline 5 August $2017^{1}$ & 12.4 & 15 & 1.9 \\
\hline 11 August $2017^{2}$ & 31.8 & 3793 & 6.1 \\
\hline 16 August $2017^{1}$ & 3.2 & 18 & 2.5 \\
\hline 18 August $2017^{2}$ & 32.4 & 1816 & 1.8 \\
\hline 21 August $2017^{1}$ & 46.4 & 957 & 2.9 \\
\hline 27 August $2017^{1}$ & 27.8 & 1017 & 4.0 \\
\hline 10 September $2017^{1}$ & 13.8 & 99 & 13.9 \\
\hline
\end{tabular}

Notes: ${ }^{1}$-these 11 events for all three MIDPs $(6,12$, and $24 \mathrm{~h}),{ }^{2}$ - these three events for MIDP $=24 \mathrm{~h}$ only, and additional events for MIDP $=6$ or $12 \mathrm{~h}$ are given in Table 3 .

Table 3. Rainfall events affected by MIDPs during the monitoring period.

\begin{tabular}{|c|c|c|c|c|c|c|c|c|}
\hline \multicolumn{3}{|c|}{ MIDP $=6 \mathrm{~h}$} & \multicolumn{3}{|c|}{ MIDP $=12 \mathrm{~h}$} & \multicolumn{3}{|c|}{ MIDP $=24 \mathrm{~h}$} \\
\hline Date & $\begin{array}{l}\text { Depth (mm), } \\
\text { Duration (min), } \\
\text { ADP (d) }\end{array}$ & R3 $(\%)^{2}$ & Date & $\begin{array}{l}\text { Depth (mm), } \\
\text { Duration (min), } \\
\text { ADP (d) }\end{array}$ & R3 (\%) ${ }^{2}$ & Date & $\begin{array}{l}\text { Depth (mm), } \\
\text { Duration (min), } \\
\text { ADP (d) }\end{array}$ & R3 $(\%)^{2}$ \\
\hline $\begin{array}{l}18 \text { July } \\
18 \text { July }^{1}\end{array}$ & $\begin{array}{c}3.8,157,2.9 \\
4.8 .43,0.4\end{array}$ & $\begin{array}{l}99.4 \\
99.9\end{array}$ & 18 July & $8.6,799,2.9$ & 99.7 & & & \\
\hline $\begin{array}{l}20 \text { July } \\
21 \text { July }\end{array}$ & $\begin{array}{c}15.4,135,2.1 \\
3.8,284,0.3\end{array}$ & $\begin{array}{c}99.4 \\
100\end{array}$ & 20 July & $19.2,841,2.1$ & 99.5 & & & \\
\hline $\begin{array}{l}11 \text { August } \\
11 \text { August }^{1}\end{array}$ & $\begin{array}{l}4.4,126,6.1 \\
5.4,217,0.2\end{array}$ & $\begin{array}{l}99.9 \\
98.7\end{array}$ & 11 August & $9.8,563,6.1$ & 99.2 & & & \\
\hline 12 August & $6.6,710,0.7$ & 100 & 12 August & $6.6,710,0.7$ & 100 & 11 August & $31.8,3793,6.1$ & 98.7 \\
\hline $\begin{array}{l}13 \text { August } \\
13 \text { August }{ }^{1}\end{array}$ & $\begin{array}{c}13.0,103,0.8 \\
2.4,406,0.4\end{array}$ & $\begin{array}{l}98.0 \\
96.3\end{array}$ & 13 August & $15.4,1096,0.8$ & 97.8 & & & \\
\hline
\end{tabular}

Notes: ${ }^{1}$-events during night, and ${ }^{2}$-for TID100-1.5 EGR.

When rainfall events during the monitoring period were divided by the three MIDPs, the R3 of each EGR module differed somewhat (Table 3). Figure 2a shows the R3 for four TID100-0.5 modules; Figure $2 b$ shows the average $\mathrm{R} 3$ and corresponding standard deviations of the four EGR modules for 22 rainfall events.

In Table 3, 11 rainfall events were affected by using three MIDPs, which led to different divisions of rainfall events. The affected events had depths from 2.4 to $26.0 \mathrm{~mm}$ for 6-h MIDP and R3 from $91.2 \%$ to $100 \%$ for module TID100-1.5. As MIDP increased, rainfall depth, duration and antecedent dry period showed relatively large increases (Table 3).

Taking TID100-1.5 EGR as an example, it was found that when two events were combined into one event as MIDP was increased, R3 changed to a value lying between the R3s for the two events (Table 3). When the affected events recorded small rainfall depths, R3 changes due to different MIDPs were also small. The rainfall on 18 August was $26 \mathrm{~mm}$ (>25 mm, defined as heavy rainfall [21]), R3 for the rainfall of $6.4 \mathrm{~mm}$ on 19 August ranged from $61.3 \%$ to $86.9 \%$ (average $72.2 \%$, standard deviation of $12.2 \%$ ) and was much smaller than for small rainfall ( $<10 \mathrm{~mm}$, Figure $2 \mathrm{~b})$.

An earlier small or moderate rainfall event $(<15 \mathrm{~mm})$ may or may not have a great deal of impact on the retention rate for a later event, but when the earlier event was large enough, its impact on 
a subsequent event was significantly increased. For example, rainfall in the mornings of 18 July and 20 July had no impacts on the R3 for a similar event that night. Rainfall in the mornings of 11 and 13 August affected the R3 to a slight extent for a similar event that night (6-h MIDP). On 13 August, the depth of the second rainfall event during the night was only $2.4 \mathrm{~mm}$, giving an R3 of $100 \%$ if no rain had fallen that morning; the R3 was actually $96.3 \%$, although R3 values were greater than $95 \%$.

(a)

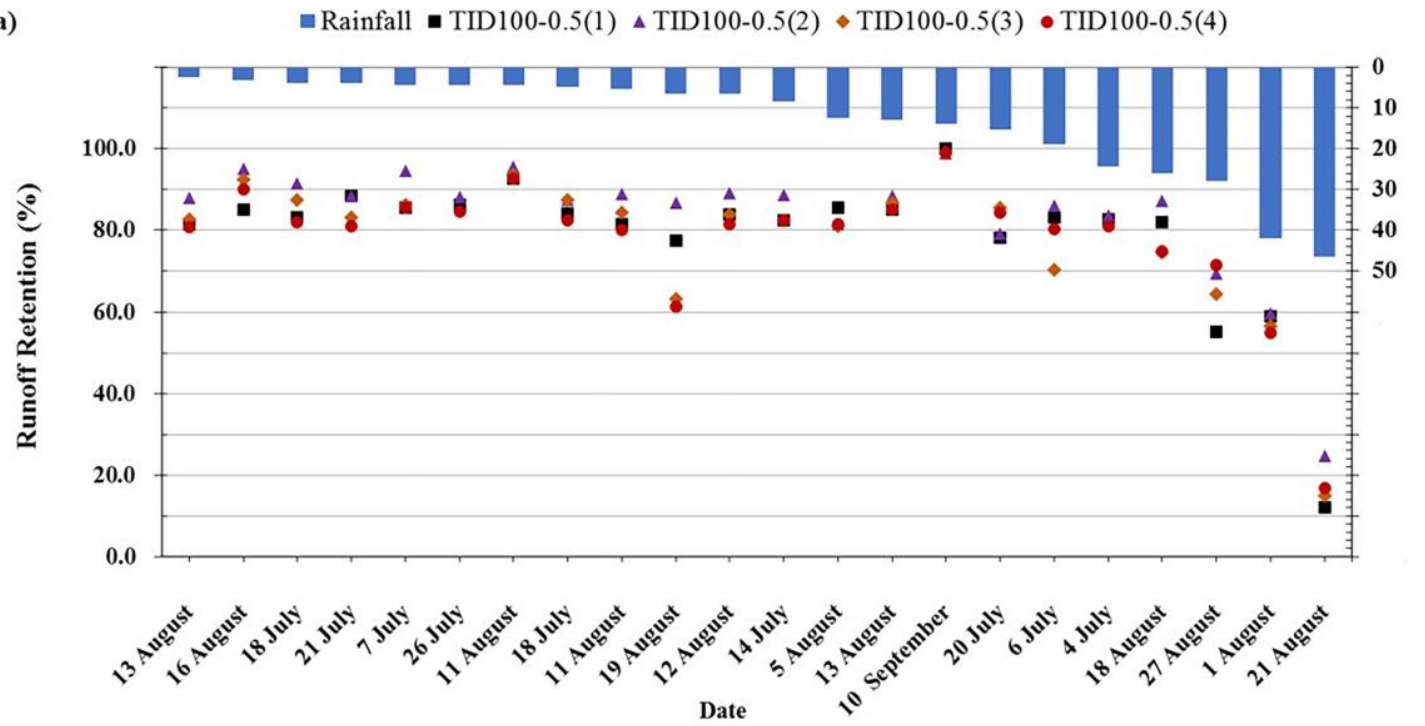

(b)

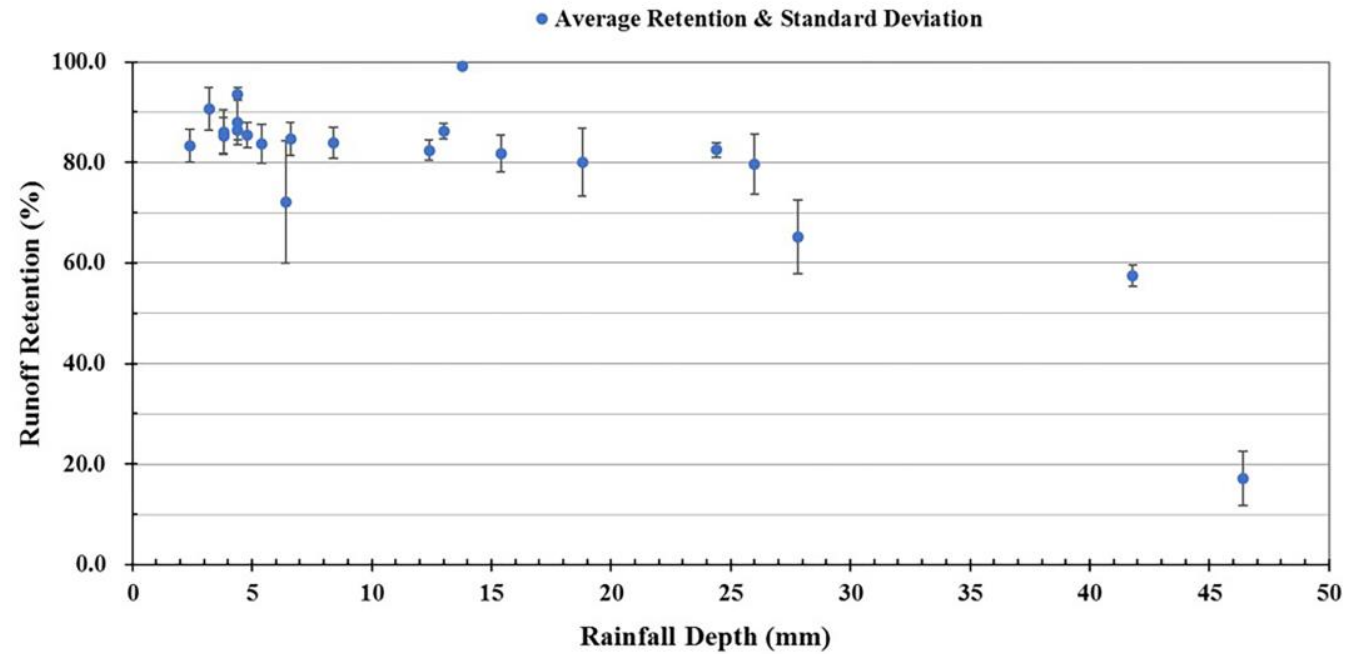

Figure 2. For the four TID100-0.5 modules: (a) runoff retention rates for 22 rainfall events and 6-h MIDPs (sorted by depth); (b) average retention rates and standard deviation for each event.

A previous study [21] suggested that the optimum retention rate for a TID100 module following $46.4 \mathrm{~mm}$ rainfall is $60 \%$. When rainfall was $46.4 \mathrm{~mm}$ on 21 August (the highest recorded rainfall), the average retention rate was only $17.2 \%$ (Figure $2 \mathrm{a}$ ). The much lower retention rate in the present case most likely resulted from heavy rainfall $(26 \mathrm{~mm})$ on 18 August and small rainfall $(6.4 \mathrm{~mm})$ on 19 August, when the EGR was still at a relatively high moisture content. The retention rate of the four EGRs for the $6.4 \mathrm{~mm}$ rainfall was $100 \%$, but the heavy rainfall on 18 August lowered the average to $72.2 \%$.

The 24-h MIDP combined five small rainfall events from 11 August to 13 August into one heavy rainfall event, and the effect of heavy rainfall on 18 August and small rainfall on 19 August vanished; therefore, use of the 24-h MIDP was probably not a good choice (too long) for separating rainfall events 
for the study of the R3 of EGRs. Not much difference was seen when rainfall events were separated by 6- and 12-h MIDPs, so $6 \mathrm{~h}$ MIDP was selected for further data analysis. The results for 22 rainfall events are presented in Figures 2-7 (11 events in Table 2 and 11 events in Table 3).

In this study, four identical EGR modules (TID100-0.5) were constructed and monitored for the same monitoring period. For the same rainfall events, the retention rates of the four modules were very similar for most events (small standard deviation for R3, Figure 2b). A few individual rainfall events (on 6 July and 18, 19, 21 and 27 August 2017) showed relatively larger differences. The standard deviation of the mean R3s for individual events (Figure 2b) lay between $0.6 \%$ and $12.2 \%$ (average 3.9\%, and $<7.4 \%$ for 21 of the events) when a 6-h MIDP was applied (Figure $2 b$ ).

The ANOVA results showed that the mean R3 of the four EGR modules were not significantly different, since one-factor ANOVA analysis gave a $p=0.64$, much greater than 0.05 . Their mean retention rate was between $77.9 \%$ and $83.7 \%$ for the 22 events (Tables 2 and 3) since the differences (maximum 5.8\%) of the means were much smaller than the individual variations (15.7-18.2\%) of R3 over 22 rainfall events. Therefore, except for four TID100-0.5 modules, the retention data of other EGR modules with variation in design parameters (Table 1) were analyzed and presented below from one module for each type of green roofs even though we had two replicates for each variation. Two replicates of TID100-1.0, TID100-1.5, and TID200-0.5 modules had monitored data but the retention difference between replicates was small. For other three modules TID150-0.5, TUD100-1.5, and TIC100-0.5, some plants of one of the EGR module replicates did not grow well due to late planting time. The retention data collected were not representative and not analyzed/presented hereafter.

The ANOVA analysis of the retention rates was first conducted between each of the four TID100-0.5 modules and one module with parameter variation. It was found ANOVA analysis results were the same no matter which module of the four TID100-0.5 EGRs was used. Therefore, for the following analyses, R3s from one of the four TID100-0.5 EGR modules for the 22 rainfall events were used and presented in a side-by-side comparison with the runoff retentions from one EGR module with variation in design parameters.

\subsection{Factors Affecting Runoff Retention of EGR}

\subsubsection{Scale of EGR Modules}

Three EGR modules (TID100-0.5, TID100-1.0 and TID100-1.5) were used to analyze the impact of the scale of EGRs on the retention performance under natural rainfall events (Figure 3) for the period 1 July-30 September 2017. For the events with rainfall less than $25 \mathrm{~mm}$, both TID100-1.0 and TID100-1.5 modules had a mean R3 of more than 97.8\%; the R3 for the TID100-0.5 module was $84.8 \%$. Despite the differences in the R3 for the three sizes of modules, the trends of their retention performances were similar.

When rainfall depth exceeded $25 \mathrm{~mm}$, the retention performance of all modules decreased significantly. When the antecedent dry period and rainfall duration were relatively short (e.g., on 21 August), although the rainfall depth $(46.4 \mathrm{~mm})$ was almost the same as on 1 August $(41.8 \mathrm{~mm})$, the retention rates of all modules was significantly reduced.

The analysis also showed that there may have been certain differences between the three modules (Figure 3), reflected in the one-factor ANOVA $p$-value of $9.01 \times 10^{-5}$ (smaller than 0.05). A comparison of the larger modules (TID100-1.0 and TID100-1.5) only, however, indicated a much smaller difference between them $(p=0.37$, much greater than 0.05$)$. Further analysis by Tukey's test indicated that there was a significant difference between them only when their average R3s varied by more than $6.5 \%$, whereas the data showed that the average difference was only $2.8 \%$ (difference between $96.2 \%$ and 93.4\%) for TID100-1.0 and TID100-1.5. When the three module types were compared, the maximum difference of average R3s reached $17.4 \%$ (difference between $96.2 \%$ and $78.8 \%$ ). This indicates that although the size of the module did not affect the overall retention trend of the green roof performance over 22 rainfall events, it did affect the runoff retention rate of the green roof for some rainfall events. 
This may have been be due to the fact that when the substrate is relatively dry, the size of the gap between the substrate and the inner wall of the small module was proportionally larger than in the larger modules (gap effect). Rainwater may then directly flow out of the module through the gap until the soil swells, with the apparent effect of lowering the retention rate. The gap effect is less in larger modules. However, many small-scale EGR modules (i.e., $0.3 \times 0.3 \mathrm{~m} ; 1.1 \mathrm{~m}^{2}$ ) are also used in actual projects or in research $[18,23]$. As a result, small EGR modules $(0.5 \times 0.5 \mathrm{~m})$ were mostly used in the present study to analyze the retention performance of EGRs. In a future study, the contribution of retention performance of actual EGR projects will also be analyzed.

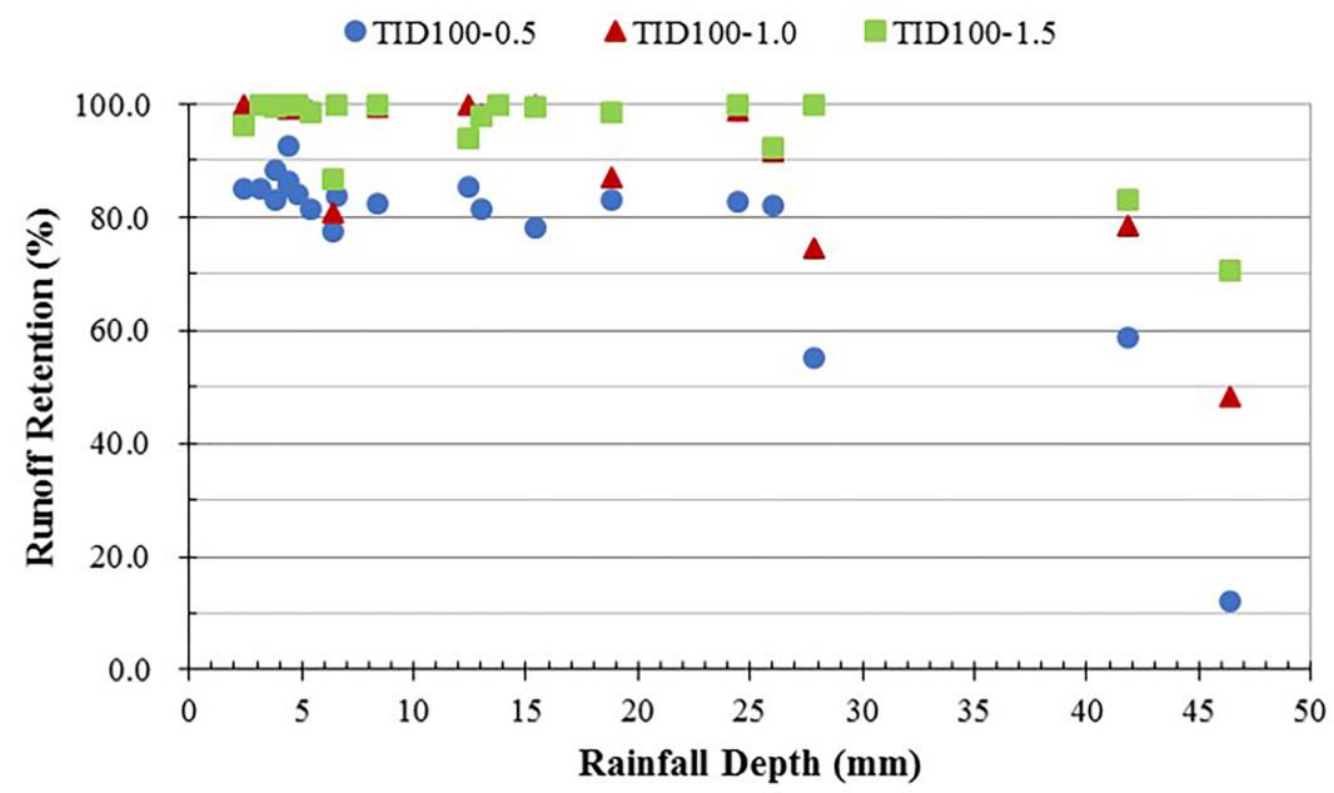

Figure 3. Rainfall retention rates R3 varying with different scale of EGR modules under 22 monitored rainfall events.

\subsubsection{Substrate Hydraulic Conductivity}

The total retention volume of TUD100-0.5 with ultra-low weight substrate was $22.4 \mathrm{~mm}$ less than the retention volume of the TID100-0.5 module with improved soil. The average R3 of TUD100-0.5 was 3.7\% lower than for the TID100-0.5 module for 22 rainfall events, which is a similar trend to our previous study in 2015 [21]. For rainfalls less than $25 \mathrm{~mm}$, both TID100-0.5 and TUD100-0.5 demonstrated good retention performance on runoff (R3 > 78\%; average R3 of 85.3\% and 82.7\%, respectively). The only exception was for the rainfall events on 6 July and 19 August, when the R3 of TUD100-0.5 was only $38.5 \%$ and $49.4 \%$, respectively. For events with rainfall $>25 \mathrm{~mm}$, the differences in the retention performances were more pronounced. In the monitored period, due to other factors such as antecedent dry period, substrate moisture, and rainfall depth, the absolute differences in R3 for individual rainfall events ranged between $0.3 \%$ and $44.7 \%$. Six events resulted in an absolute difference $>10 \%$ (average $21.4 \%$ ). Therefore, the retention performance of EGR with lower substrate hydraulic conductivity had fewer random variations in response to rainfall depth and was superior to the module with higher substrate hydraulic conductivity.

One-factor variance analysis $(p=0.58$, much larger than 0.05$)$ and Tukey's test results showed no significant difference between the mean retention rates for these two modules. This indicates that due to the large variation in retention performance (12.1-100\%) over 22 rainfall events, even modules TID100 and TUD100 had greatly different R3 for several events (Figure 4), the mean retention performances of these two EGRs were not significantly different. Even though the hydraulic conductivity of the substrate differed by a factor of about 4 , there was only a small difference in the retention of runoff. 
Chow et al. [24] used burnt soil and potting soil to test the runoff retention performance of EGRs with substrate hydraulic conductivities of $1.18 \times 10^{-6} \mathrm{~m} / \mathrm{s}$ and $0.75 \times 10^{-6} \mathrm{~m} / \mathrm{s}$, respectively. In their study, regardless of whether grasses or sedum plants were used in the plant layer of green roofs, the burnt soil with a higher substrate hydraulic conductivity had a slightly better retention effect than the potting soil, but the difference was not significant. The reason may be that the hydraulic conductivities of both substrates was much smaller than those in the present study, and the rainfall events they monitored were mostly small and medium rainfall $(<19.0 \mathrm{~mm})$, so the difference was not obvious.

Stovin et al. [12] obtained similar results for three different substrates (heather with lavender, sedum carpet and light expanded clay aggregate) to test the hydrological performance of the EGRs. They found that the hydraulic conductivity of the substrate was inversely proportional to the retention capacity, which is consistent with the results of the present study, since the rainfall depths in the six rainfall events they monitored were larger than those in Chow's study.

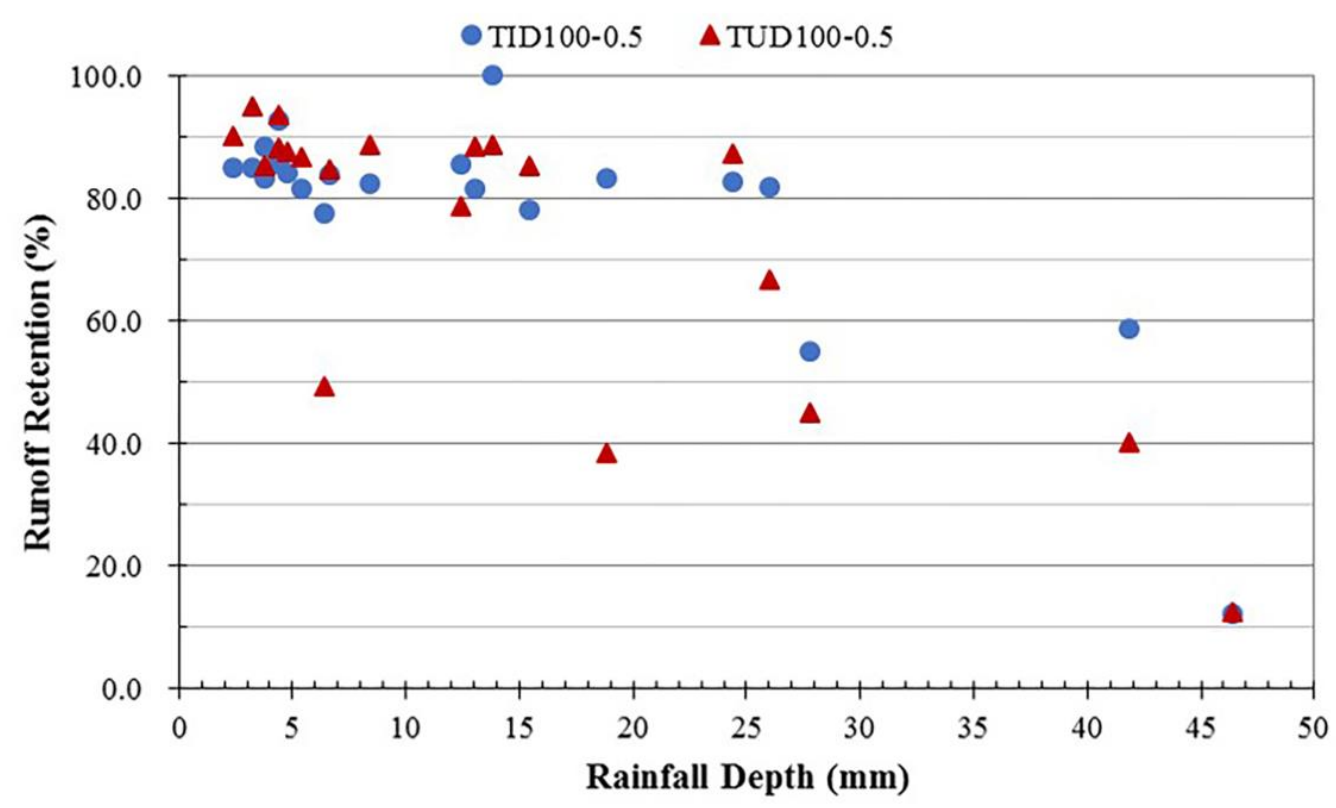

Figure 4. Rainfall retention rates R3 varying with different substrate hydraulic conductivity of EGR modules under the monitoring period.

\subsubsection{Substrate Depth}

Rainfall-runoff data from 1 July to 30 September 2017 for TID100-0.5, TID150-0.5 and TID200-0.5 (Table 2) was analyzed to determine the effect of substrate depth (100, 150 and $200 \mathrm{~mm})$ on runoff retention (Figure 5). The retention performance of TID200-0.5 was the best except in one rainfall event on 5 August 2017, in which TID100 had better retention performance than both TID150 and TID200 (Figure 5). The R3 of TID200 ranged from 57.6\% to 100\% (average of $89.1 \%$ ) for the 22 rainfall events. The runoff retention of TID150-0.5 was basically consistent with that of TID200-0.5 but slightly lower for each rainfall event (average of 4.9\%) than for TID200-0.5. The total cumulative runoff retention rates for TID100-0.5, TID150-0.5 and TID200-0.5 over the monitoring period were 66.6\%, $77.6 \%$, and $83.7 \%$, respectively. In addition, when the rainfall depth increased gradually, the retention rates of TID150-0.5 and TID200-0.5 slowly decreased. The average R3 of TID150-0.5 was 5.4\% higher than that of TID100-0.5, and TID200-0.5 was 4.8\% higher than for TID150-0.5; that is, $10.2 \%$ higher than TID100-0.5. Many previous studies have obtained similar results [16,25-27]. Dusza et al. [26] found a strong difference in runoff retention for different substrate thicknesses. 
Although a thicker substrate layer slightly improves retention performance, one-factor variance analysis $(p>0.05)$ and Tukey's test results both showed no significant difference in the mean retention rates of the three substrate thicknesses $(78.8 \%, 84.3 \%$ and $89.1 \%$ for TID100, TID150 and TID200, respectively). This is because of the large standard deviation (standard deviation $=17.6 \%$ for TID100) from the R3 over 22 rainfall events. Also, merely increasing the substrate layer thickness is not desirable in practice; it increases the costs and subjects the roof to larger loads. Comparing our experiments in 2015 [21] for EGRs for substrate thicknesses of $20 \mathrm{~mm}$ and $50 \mathrm{~mm}$ to the current study, with substrate thicknesses of $150 \mathrm{~mm}$ and $200 \mathrm{~mm}$, it is found that with a substrate layer of $100 \mathrm{~mm}$, the TID100 module achieved good retention performance overall and ensured normal plant growth at lower cost.

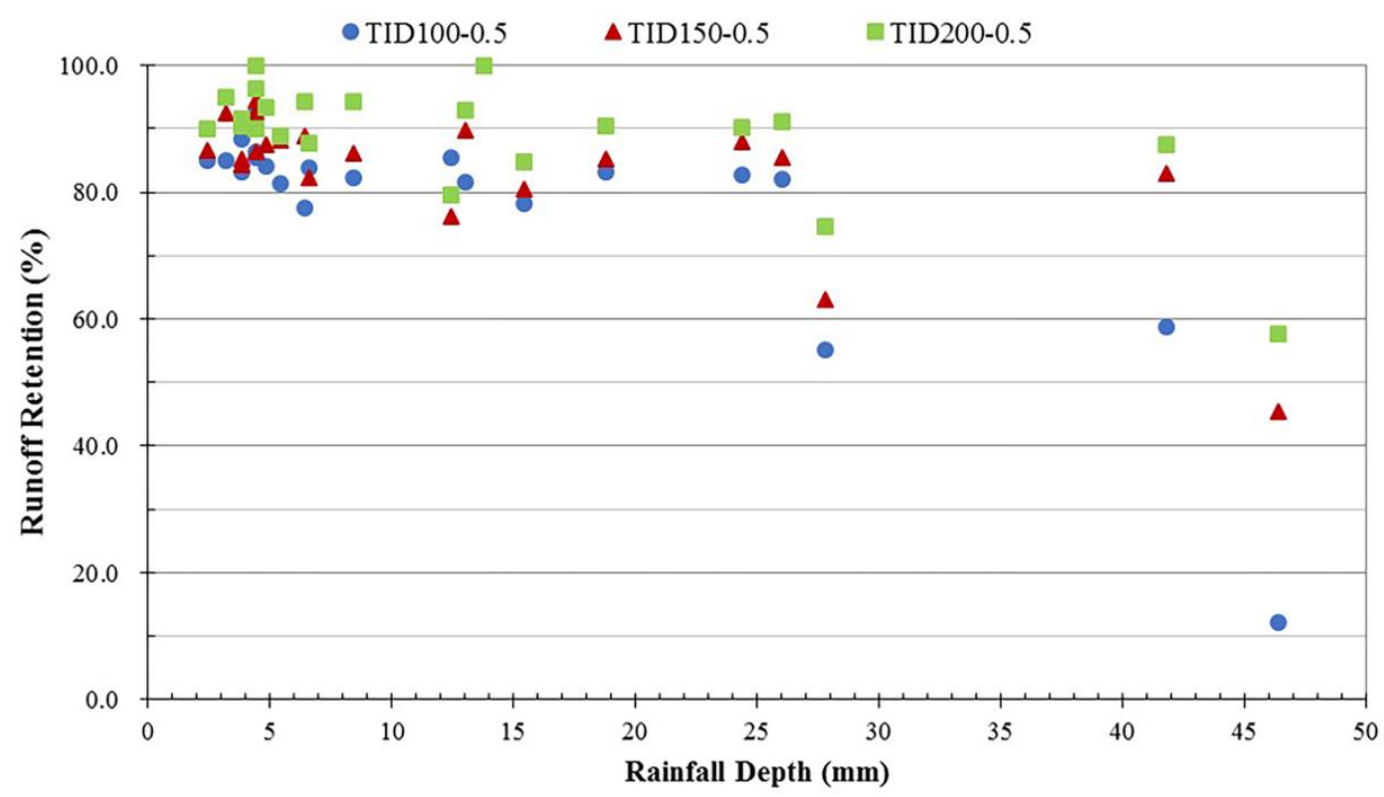

Figure 5. Rainfall retention rates R3 varying with different substrate depths of EGR modules under 22 monitored rainfall events.

\subsubsection{Drainage Layer}

Rainfall-runoff data for modules TID100-0.5 and TIC100-0.5 were used to analyze the effect of their drainage layer materials on their runoff retention. The retention performance of both types of drainage layer was very similar for all 22 monitored rainfall events (Figure 6). The average absolute difference was $3.6 \%$ ( 17 events $<8.5 \%$ difference).

One-factor variance analysis ( $p=0.76$, much greater than 0.05$)$ and Tukey's test results also showed no significant difference in mean retention for these two modules.

Vesuviano and Stovin [28] tested four different types of ZinCo drainage layer to determine their hydrological performance. The results were similar to the findings of the present study for all modules, the sole exception being a slight delay in the beginning of runoff starting time.

Vila et al. [29] developed a new type of drainage layer material of rubber crumbs to be used instead of puzolana, a commercially available material. The pore size of the rubber crumbs was divided into three types (big, half, and small). Basically, no difference was found on the runoff retention of EGRs, although their ability to retain runoff was slightly higher than the previous material, which reflects the findings that the drainage layer material has little effect on runoff retention, but the drainage layer is indispensable in the green roof structure. 


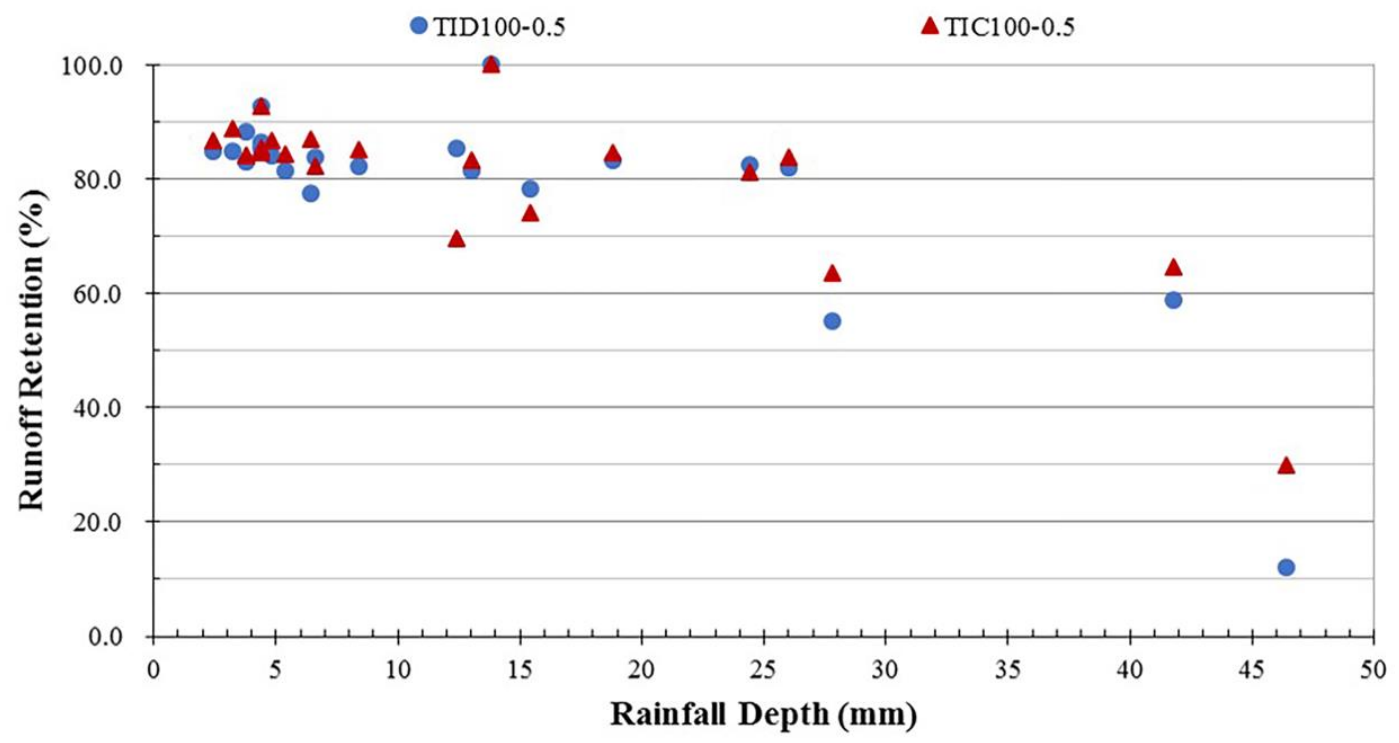

Figure 6. Rainfall retention rates R3 varying with different drainage layer types of EGR modules under 22 monitored rainfall events.

\subsubsection{Rainfall Characteristics}

For natural rainfall events, characteristics such as rainfall depth $(\mathrm{P})$, rainfall intensity and antecedent dry period all have a large influence on the retention effect of EGRs, as indicated by Hakimdavar et al. [18]. Rainfall-runoff data for 1 July-30 September 2017 for the four TID100-0.5 modules was analyzed. (Figure 7). The average R3 of the four modules for small rainfall events $(\mathrm{P} \leq 10 \mathrm{~mm})$ was $85.3 \%$, average retention of $85.4 \%$ for medium rainfall events $(10 \mathrm{~mm}<\mathrm{P} \leq 25 \mathrm{~mm})$ and $54.9 \%$ for rainfall events $P>25 \mathrm{~mm}$.

When using rainfall depth as a controlling factor for ANOVA input, we assumed that four replicated experiments were conducted. Rainfall events with different rainfall depths had a significant impact on the R3 of the modules, since $p=1.07 \times 10^{-31}<<0.05$. When rainfall events were sorted by rainfall depth, there is still a significant difference in the mean retention performance of TID100 under small, medium and large rainfall events. For $46.4 \mathrm{~mm}$ rainfall, the average R3 of the TID100-0.5 was only $17.2 \%$ (Figure 2).

Although other factors such as climatic conditions may also cause deviation in experimental results for natural rainfall, the relations of runoff retention of EGR modules versus rainfall depth are consistent with many other studies [3,12]. Hakimdavar et al. [18] reported that, from an EGR study in Manhattan, New York, $85 \%$ retention for rainfall events $<20 \mathrm{~mm}, 62 \%$ for medium events of $20-40 \mathrm{~mm}$, and $51 \%$ for events $>40 \mathrm{~mm}$. Carter and Rasmussen [8] reported the green roof had a beneficial effect on the retention of stormwater runoff, based on data collected from 1 to 30 November 2014.

Figure $7 \mathrm{a}$ shows that the rainfall duration seems to have no strong correlation with runoff retention by EGR modules for all 22 rainfall events. Excluding the $46.4 \mathrm{~mm}$ rainfall event, the linear correlation between R3 and duration is 0.57 . This is similar to the finding of the study by Speak et al. [30], but is somewhat different from two other studies $[9,18]$.

Bliss et al. [9] monitored runoff reduction ( $7 \%-69 \%$ by volume) of a prototype green roof $\left(1150 \mathrm{~m}^{2}\right)$ for 13 rainfall events in the Pittsburgh area from August 2006-January 2007 and compared it with a conventional ballasted membrane roof $\left(1950 \mathrm{~m}^{2}\right)$. The linear correlation between runoff volume reduction of the prototype green roof and duration was 0.25 for all 13 rainfall events. 
(a)

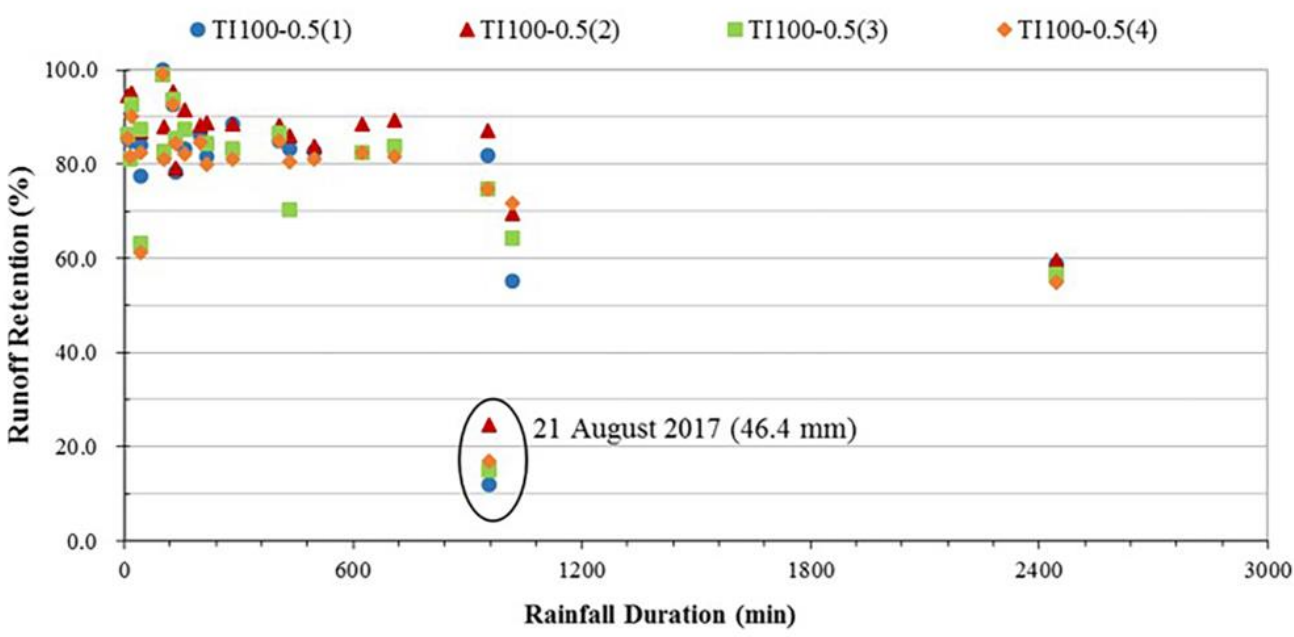

(b)

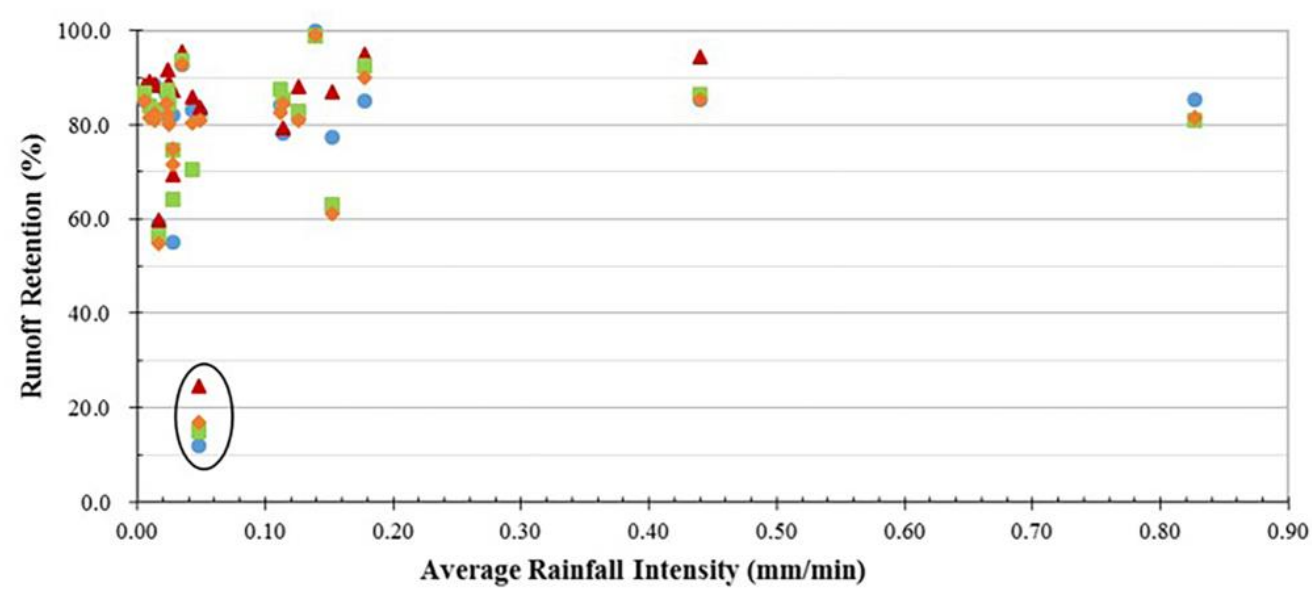

(c)

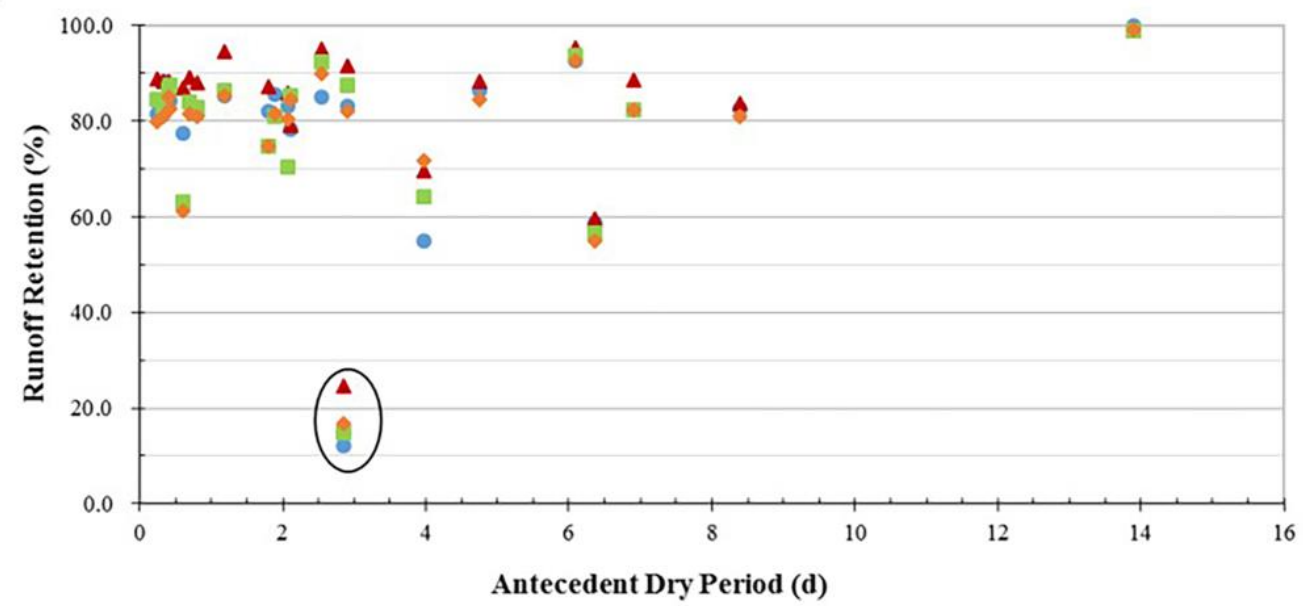

Figure 7. Rainfall retention rates for four TID100-0.5 EGR modules, for rainfall characteristics (a) rainfall duration; (b) average rainfall intensity; and (c) antecedent dry period.

The present study covered more short-duration small-depth events than were observed by Bliss et al. [9]. Hakimdavar et al. [18] also indicated that the capacity of runoff retention decreased with longer rainfall events, mainly due to the positive correlation between rainfall depth and rainfall duration in the monitored rainfall events. Therefore, rainfall depth has more influence on the retention capacity of EGRs than rainfall duration. 
Figure $7 \mathrm{~b}$ indicates that the average rainfall intensity of 22 rainfall events in the present study seems to have had very little effect on the retention capacity of EGR modules, which is similar to the finding from the study by Hakimdavar et al. [18]. For example, the average rainfall intensity was the same for rainfall events on 26 July 2017 (4.4 mm) and 1 August $2017(41.8 \mathrm{~mm})$, but the TID100-0.5 modules retention performance was very different: the mean retention rates for these two events were $86.4 \%$ and $57.5 \%$, respectively. The same experimental results also appeared on 4 July $(24.4 \mathrm{~mm})$ and 21 August $(46.4 \mathrm{~mm}$ ) (average retention rates $82.5 \%$ and $17.2 \%$, respectively). The differences in R3 may be due to the fact that the rainfall depth and rainfall durations were quite different for these compared rainfall events with similar average rainfall intensity.

Alfredo et al. [19] studied the runoff peak reduction of green roof test plots $\left(1.22 \times 0.61 \mathrm{~m}^{2}\right)$ under simulated rainfall events. Their results indicated that a 5-min intensity of rainfall increase reduced the retention effect of the green roof, which differs from the information presented on Figure $7 \mathrm{~b}$. This is because of the different methods used to calculate rainfall intensity in the different research [30-32].

On 10 September, the rainfall depth was $13.8 \mathrm{~mm}$, since the antecedent dry period was 14 days, the R3s were $\sim 100 \%$ for all four TID100-0.5 modules (Figure 7c) and for all other TID or TIC modules (Figures 3-6) except TUD100-0.5 EGR (Figure 5). The near 100\% retention is generally true as the soil is quite dry when the antecedent dry period is long and rainfall is small. Except for the above case, Figure 7c shows that antecedent dry periods up to 14 days had little effect on runoff retention. One-factor ANOVA results, as in the study (inter-event dry period (IDP) up to 10 days) of Hakimdavar et al. [18] also showed that the effect of the antecedent dry period on runoff retention was not significant since $p>>0.05$. The study in Sheffield, UK, by Stovin et al. [33] differed. They collected rainfall-runoff data on green-roof test plots $(1 \times 3 \mathrm{~m}$, using a mixture of crushed brick and fines as substrate) and found that an antecedent dry period $<2$ days or $>2$ days had a significant impact on the rainfall-runoff linear relationships of EGRs for small or moderate rainfall depths $(\approx 3-21 \mathrm{~mm})$. The relatively dry climate in Beijing in comparison to the humid oceanic climate in Sheffield (average 13-16 days of rainfall per month) may cause different EGR drying times and affect the runoff retention under different IDPs.

\section{Conclusions}

In this study, a complete multi-factor green-roof runoff-retention performance analysis was conducted. The rainfall-runoff data of 22 natural rainfalls from 1 July to 30 September 2017 (using $6 \mathrm{~h}$ MIDP to separate rainfall events) were used to comprehensively analyze the influencing factors and retention performance of 10 EGRs (Sedum lineare Thunb. vegetation layer for all modules). The important conclusions of this study are as follows:

(1) Larger MIDPs cause increases in depth, duration and antecedent dry periods for rainfall events, which also affect the correlation of the retention performance of EGRs with rainfall characteristics. Three different MIDPs: 6-, 12- and 24-h, were used to separate rainfall events; 24-h MIDP was too long to appropriately combine several small rainfall events and eliminate the impact of a heavy rainfall on the retention performance of a coming small rainfall event. MIDP of $6 \mathrm{~h}$ was used to analyze the runoff retention performances of 10 EGR test modules under 22 rainfall events (2.4-46.4 mm). Small or moderate rainfall $(<15 \mathrm{~mm})$ for an earlier event may or may not have much impact on the retention rate for the next rainfall event, and heavy rainfall $(>25 \mathrm{~mm}$ ) definitely affected the retention performance of EGRs in the next rainfall event with short inter-event dry period (e.g., $<2$ days).

(2) Substrate hydraulic conductivity, substrate depth and rainfall depth were the main factors affecting the retention performance of the EGRs. When the hydraulic conductivity of the TUD100-0.5 substrate (ultra-low weight substrate) was about four times larger than the improved soil of TID100-0.5, the runoff retention performance of TUD100-0.5 was weakened and had greater variation (Figure 4).

When the substrate depth was increased from 100 to $150 \mathrm{~mm}$ and from 100 to $200 \mathrm{~mm}$, R3 increased by $5.4 \%$ and $10.2 \%$, respectively. The retention performance of EGRs decreased with the increase of rainfall depth when the rainfall was $>20 \mathrm{~mm}$. The R3 of TID100-0.5 EGR modules was $84.8 \%$ (standard 
deviation $=5.1 \%$ ) for $<25 \mathrm{~mm}$ rainfall. When rainfall was $46.4 \mathrm{~mm}$ on 21 August (deepest rainfall), the R3 was $12.1 \%$, which was greatly impacted by heavy rainfall $(26 \mathrm{~mm})$ on 18 August and small rainfall $(6.4 \mathrm{~mm})$ on 19 August.

(3) ANOVA and Tukey's test results showed no significant difference in the retention performance between TID100-0.5 and TIC100-0.5 that had drainage layers of different material. Neither rainfall duration, rainfall intensity nor antecedent dry period were strongly correlated with EGR retention performance compared with rainfall depth ( $p>0.05$ in all cases).

However, the above conclusions were only valid for EGR test modules (0.5-1.5 m box sizes) with the specific substrates used in this study in the relatively dry Beijing climate, all of which were different from some previous studies.

Author Contributions: D.Y. did the experiments, collected basic rainfall-runoff data, result analysis and prepared the manuscript draft. X.F. supervised data analysis and revised the manuscript. Y.G. and J.L. supervised the writing, data analysis, and revised the manuscript. All authors made contributions to the study and writing the manuscript.

Funding: This research was funded by the State Key Program of National Natural Science of China grant number [51879004 and 41530635] and Beijing University of Civil Engineering and Architecture Research Fund for Pyramid Talents Development and Beijing Higher Education High Level Teachers Team Construction Program grant number [CIT\&TCD201704055].

Conflicts of Interest: The authors declare no conflict of interest.

\section{References}

1. Jiang, Y.; Zevenbergen, C.; Ma, Y. Urban pluvial flooding and stormwater management: A contemporary review of China's challenges and "Sponge Cities" strategy. Environ. Sci. Policy 2018, 80, 132-143. [CrossRef]

2. Jia, H.; Yao, H.; Yu, S.L. Advances in LID BMPs research and practice for urban runoff control in China. Front. Environ. Sci. Eng. 2013, 7, 709-720. [CrossRef]

3. Zhang, Q.; Miao, L.; Wang, X.; Liu, D.; Zhu, L.; Zhou, B.; Sun, J.; Liu, J. The capacity of greening roof to reduce stormwater runoff and pollution. Landsc. Urban Plan. 2015, 144, 142-150. [CrossRef]

4. Ran, J.; Tang, M. Effect of green roofs combined with ventilation on indoor cooling and energy consumption. Energy Procedia 2017, 141, 260-266. [CrossRef]

5. Coma, J.; Pérez, G.; Solé, C.; Castell, A.; Cabeza, L.F. Thermal assessment of extensive green roofs as passive tool for energy savings in buildings. Renew. Energy 2016, 85, 1106-1115. [CrossRef]

6. Soulis, K.X.; Ntoulas, N.; Nektarios, P.A.; Kargas, G. Runoff reduction from extensive green roofs having different substrate depth and plant cover. Ecol. Eng. 2017, 102, 80-89. [CrossRef]

7. Vijayaraghavan, K.; Raja, F.D. Design and development of green roof substrate toimprove runoff water quality: Plant growth experiments and adsorption. Water Res. 2014, 63, 94-101. [CrossRef] [PubMed]

8. Carter, T.L.; Rasmussen, T.C. Hydrologic behavior of vegetated roofs. JAWRA J. Am. Water Res. Assoc. 2010, 42, 1261-1274. [CrossRef]

9. Bliss, D.J.; Neufeld, R.D.; Ries, R.J. Storm water runoff mitigation using a green roof. Environ. Eng. Sci. 2009, 26, 407-418. [CrossRef]

10. Lee, D.K.; Oh, S.H.; Yoon, S.W.; Jang, S.W. A field study to evaluate green roof runoff reduction and delay. J. Korea Soc. Environ. Restor. Technol. 2006, 9, 117-122.

11. Baek, S.Y.; Kim, H.W.; Kim, M.K.; Han, M.Y. Runoff reduction effect of rainwater retentive green roof. KIEAE J. 2016, 16, 67-71. [CrossRef]

12. Stovin, V.; Poë, S.; De-Ville, S.; Berretta, C. The influence of substrate and vegetation configuration on green roof hydrological performance. Ecol. Eng. 2015, 85, 159-172. [CrossRef]

13. Berretta, C.; Poë, S.; Stovin, V. Moisture content behaviour in extensive green roofs during dry periods: The influence of vegetation and substrate characteristics. J. Hydrol. 2014, 511, 374-386. [CrossRef]

14. Nagase, A.; Dunnett, N. Amount of water runoff from different vegetation types on extensive green roofs: Effects of plant species, diversity and plant structure. Landsc. Urban Plan. 2012, 104, 356-363. [CrossRef]

15. Sia, M.E. Evapotranspiration from Extensive Green Roofs: Influence of Climatological Conditions, Vegetation Type, and Substrate Depth. Master's Thesis, Western University, London, ON, Canada, 2016. 
16. Van Woert, N.D.; Rowe, D.B.; Andresen, J.A.; Rugh, C.L.; Fernandez, R.T.; Xiao, L. Green roof stormwater retention: Effects of roof surface, slope, and media depth. J. Environ. Qual. 2005, 34, 1036-1044. [CrossRef] [PubMed]

17. Zhang, Z.; Szota, C.; Fletcher, T.D.; Nsg, W.; Werdin, J.; Farrell, C. Influence of plant composition and water use strategies on green roof stormwater retention. Sci. Total Environ. 2018, 625, 775-781. [CrossRef] [PubMed]

18. Hakimdavar, R.; Culligan, P.J.; Finazzi, M.; Barontini, S.; Ranzi, R. Scale dynamics of extensive green roofs: Quantifying the effect of drainage area and rainfall characteristics on observed and modeled green roof hydrologic performance. Ecol. Eng. 2014, 73, 494-508. [CrossRef]

19. Alfredo, K.; Montalto, F.; Goldstein, A. Observed and modeled performances of prototype green roof test plots subjected to simulated low and high-intensity precipitations in a laboratory experiment. J. Hydrol. Eng. 2010, 15, 444-457. [CrossRef]

20. Chen, C.F. Performance evaluation and development strategies for green roofs in Taiwan: A review. Ecol. Eng. 2013, 52, 51-58. [CrossRef]

21. Gong, Y.W.; Yin, D.K.; Fang, X.; Zhai, D.D.; Li, J.Q. Rainwater retention effect of extensive green roofs monitored under natural rainfall events-A case study in Beijing. Hydrol. Res. 2018. Available online: https:/ / doi.org/10.2166/nh.2018.144 (accessed on 4 September 2018).

22. Wanielista, M.P.; Yousef, Y.A. Stormwater Management, 1st ed.; Wiley-Interscience: Hoboken, NJ, USA, 1993; pp. 66-67.

23. Wong, G.K.L.; Jim, C.Y. Quantitative hydrologic performance of extensive green roof under humid-tropical rainfall regime. Ecol. Eng. 2014, 70, 366-378. [CrossRef]

24. Chow, M.F.; Bakar, M.F.A.; Sidek, L.M.; Basri, H. Effects of substrate types on runoff retention performance within the extensive green roofs. J. Eng. Appl. Sci. 2017, 12, 5379-5383.

25. Soulis, K.X.; Valiantzas, J.D.; Ntoulas, N.; Kargas, G.; Nektarios, P.A. Simulation of green roof runoff under different substrate depths and vegetation covers by coupling a simple conceptual and a physically based hydrological model. J. Environ. Manag. 2017, 200, 434-445. [CrossRef] [PubMed]

26. Dusza, Y.; Barot, S.; Kraepiel, Y.; Lata, J.C.; Abbadie, L.; Raynaud, X. Multifunctionality is affected by interactions between green roof plant species, substrate depth, and substrate type. Ecol. Evolut. 2017, 7, 2357-2369. [CrossRef] [PubMed]

27. Buccola, N.; Spolek, G. A pilot-scale evaluation of greenroof runoff retention, detention, and quality. Water Air Soil Pollut. 2011, 216, 83-92. [CrossRef]

28. Vesuviano, G.; Stovin, V. A generic hydrological model for a green roof drainage layer. Water Sci. Technol. J. Int. Assoc. Water Pollut. Res. 2013, 68, 769-775. [CrossRef] [PubMed]

29. Vila, A.; Pérez, G.; Solé, C.; Fernández, A.I.; Cabeza, L.F. Use of rubber crumbs as drainage layer in experimental green roofs. Build. Environ. 2012, 48, 101-106. [CrossRef]

30. Speak, A.F.; Rothwell, J.J.; Lindley, S.J.; Smith, C.L. Rainwater runoff retention on an aged intensive green roof. Sci. Total Environ. 2013, 461-462, 28-38. [CrossRef] [PubMed]

31. Rahmah, K.; Ghani, A.A.; Zakaria, N.A.; Shaharudin, S. Efficiency of intensive green roof in high intensity rainfall for stormwater treatment: Selection of vegetations. In Proceedings of the 36th TAHR Word Congress, Hague, The Netherlands, 28 June-3 July 2015; pp. 6730-6735.

32. Razzaghmanesh, M.; Beecham, S. The hydrological behaviour of extensive and intensive green roofs in a dry climate. Sci. Total Environ. 2014, 499, 284-296. [CrossRef] [PubMed]

33. Stovin, V.R.; Dunnett, N.; Hallam, A. Green roofs-Getting sustainable drainage off the ground. In Proceedings of the 6th International Conference of Sustainable Techniques and Strategies in Urban Water Management, Lyon, France, 25-28 June 2007; pp. 11-18.

(C) 2018 by the authors. Licensee MDPI, Basel, Switzerland. This article is an open access article distributed under the terms and conditions of the Creative Commons Attribution (CC BY) license (http:/ / creativecommons.org/licenses/by/4.0/). 